\title{
Vinasse: from a residue to a high added value biopolymer
}

\author{
Daiana V. Trapé ${ }^{1,2}$, Olivia V. López ${ }^{1,3}$ and Marcelo A. Villar ${ }^{1,2^{*}}$ (1)
}

\begin{abstract}
This work aimed to study the feasibility of using vinasse for polyhydroxybutyrate (PHB) production by Bacillus megaterium. To optimize the culture medium, a Box-Behnken design was employed considering carbon (C), nitrogen (N), and phosphorus $(\mathrm{Ph})$ concentrations as independent variables and PHB productivity as the response variable. The productivity decreased when $\mathrm{C}$ or $\mathrm{N}$ were increased, probably due to the presence of phenolic compounds and the limitation of $\mathrm{N}$ for the production of PHB by Bacillus sp. bacteria. An additional experimental design to optimize the $\mathrm{C} / \mathrm{N}$ ratio and growing conditions (fermentation time and temperature) was carried out. Fermentation time had a statistically significant effect on PHB productivity reaching $10.6 \mathrm{mg} / \mathrm{L} \mathrm{h}$. On the other hand, the variability in physicochemical properties of vinasse samples led to significant differences in PHB productivity. Lower productivity values were obtained when vinasse had higher values of $\mathrm{DBO}$. Therefore, biopolymers production from vinasse is a feasible alternative to valorize this bioethanol by-product.
\end{abstract}

Keywords: Vinasse, Polyhydroxybutyrate (PHB), Bacillus megaterium, Microbial fermentation, Culture medium optimization

Graphical Abstract

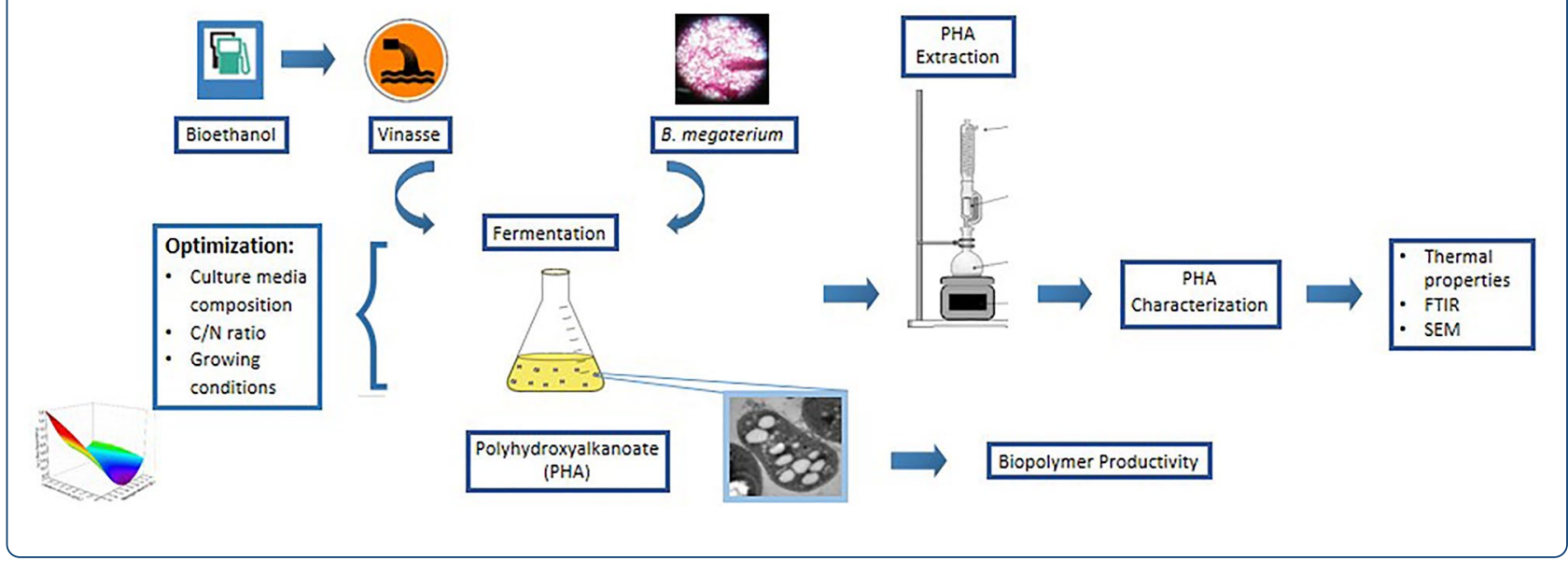

*Correspondence: mvillar@plapiqui.edu.ar

1 Planta Piloto de Ingeniería Química, PLAPIQUI (UNS-CONICET), Camino

La Carrindanga Km. 7, 8000 Bahía Blanca, Argentina

Full list of author information is available at the end of the article

\section{Introduction}

Plastics obtained from non-renewable sources are one of the most used materials in the world, they are broadly integrated into today's lifestyle and contribute to almost all product areas. However, when plastics are discarded into the environment, they can persist for very long

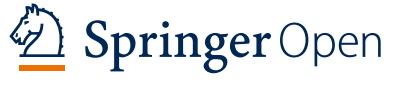

(c) The Author(s) 2021. Open Access This article is licensed under a Creative Commons Attribution 4.0 International License, which permits use, sharing, adaptation, distribution and reproduction in any medium or format, as long as you give appropriate credit to the original author(s) and the source, provide a link to the Creative Commons licence, and indicate if changes were made. The images or other third party material in this article are included in the article's Creative Commons licence, unless indicated otherwise in a credit line to the material. If material is not included in the article's Creative Commons licence and your intended use is not permitted by statutory regulation or exceeds the permitted use, you will need to obtain permission directly from the copyright holder. To view a copy of this licence, visit http://creativecommons.org/licenses/by/4.0/. 
periods of time (Andrady 2015). For this reason, in the last years, alternatives have been explored to replace petroleum derived plastics by materials obtained from natural sources. Hence, several materials have been investigated such as biobased poly(ethylene terephthalate) (bio-PET), biobased poly(ethylene) (bio-PE), biopoly(carbonate) (bio-PC), bio-poly(amide) (bio-PA), poly(hydroxyalcanoate)s (PHAs), and poly(lactic acid) (PLA), among others. PHAs are polyesters of hydroxyacids naturally synthesized by bacteria as carbon reserve. These biopolymers are accumulated as cytoplasmic inclusions in certain bacteria during unbalanced growth conditions, usually characterized by an excess of the carbon source and the lack of at least one of the essential nutrients (Kovalcik et al. 2019). Poly(3-hydroxybutyrate) (PHB) is the most common and the best known PHA and it is a great alternative to develop biomaterials since this biopolymer has similar properties to conventional polymers such as PE and poly(propylene) (PP) (Vandi et al. 2018). Also, PHB decomposes to water and carbon dioxide under aerobic conditions and to methane and carbon dioxide under anaerobic conditions by microorganisms in soil, sea, lake water, and sewage (Anjum et al. 2016). Its applications include packaging materials, bags, containers, sutures, cardiovascular stents, targeted tissue repair/ regeneration devices, polymer-based depots for controlled drug release or implants, and disposable items like single-use cups and diapers (Koller 2018).

Despite these advantages, the high production cost of PHB is the main obstacle for its commercialization. PHB cost is at least three times higher than conventional plastics such as PP and PE, attributed mainly to the expensive substrates and processing (Kourmentza et al. 2017), and similar to biobased polymers such as PLA (Kaur et al. 2017). Thus, using cheaper feedstocks is one of the keys to reduce PHB production costs. Food wastes (Nielsen et al. 2017), residues from beer breweries (Amini et al. 2020), cheese whey (Pais et al. 2016), olive mill wastewater (Alsafadi and Al-Mashaqbeh 2017), and hydrolyzed corn starch (Fabra et al. 2016) are some resources that have been investigated for sustainable PHB production. On the other hand, vinasse, a residue of the sugar cane alcohol industry, could be used as an economic substrate to produce PHB at lower costs. In this sense, some authors have reported the use of vinasse as carbon source for PHB production. Bhattacharyya et al. (2012) used vinasse with Haloferax mediterranei to produce PHAs and they reported that concentrations higher than $10 \%$ of raw vinasse inhibited the microbial growth. On the other hand, Zanfonato et al. (2018) did fermentations with Cupriavidus necator using vinasse as carbon source and no inhibitory effect was observed. Pramanik et al. (2012) employed raw vinasse as carbon source to produce PHB with Haloarcula marismortui and achieved an accumulation of $23 \%$ PHA (of cell dry weight). These authors also stressed that after a pretreatment process through adsorption on activated carbon, vinasse could be used leading to $30 \%$ accumulation. In other cases, a combination of vinasse and sugarcane molasses was used by Cupriavidus necator as microorganism (Dalsasso et al. 2019; Acosta-Cárdenas et al. 2018). They showed that vinasse can be an appropriate diluent to molasses to use as non-conventional culture medium in the production of PHAs. Nowadays, vinasse disposal represents an environmental problem since it affects water and edaphic resources, as well as the life of animal and plant species. The high solids concentration and hard constituents, such as phenols and polyphenols, contaminate the surface and underground water. Also, vinasse presence increases eutrophication due to its high content of nitrogen and phosphorus (Parsaee et al. 2019). Colored compounds of vinasse reduce the permeability of sunlight in rivers and lakes, thereby reducing the photosynthetic activity and the concentration of dissolved oxygen in water generating disturbances of plants and aquatic animal life (Syaichurrozi 2016). Vinasse is also toxic because of its low $\mathrm{pH}$, it has an unpleasant smell for humans and its influence on drinking water leads to an outbreak of malaria, amoebiasis, and schistosomiasis. It is a medium for worm eggs of Meloidogyne javanica, M. incognita, and Drosophila melanogaster to grow. The pollution of each liter of vinasse is equal to the amount of contamination produced by 1.43 humans (Parsaee et al. 2019).

Optimization of the fermentation process is another way to reduce the costs of PHB. The optimization by statistical methods, compared to the common "one factor at a time" method, proved to be a powerful and useful tool to predict the maximum yield for bioproducts synthesis. Statistical methods such as response surface methodology enable to design the experiments and to evaluate the interactions among factors and responses throughout the study (Nor et al. 2017). According to Nygaard et al. (2019), in the case of microbiological fermentation processes to produce PHAs, response surface methodology can be used to determine the composition of the culture medium that provides an optimal productivity of PHAs. Before using the response surface methodology approach, the correct experimental design must be selected to designate which treatments should be done in the experimental region being studied. For this purpose, experimental designs for quadratic response surfaces, such as three-level factorial, central composite, and Box-Behnken, should be applied (Yolmeh and Jafari 2017). A comparison between the Box-Behnken design and other response surface designs (central composite and three-level full factorial design) had demonstrate 
that Box-Behnken design is slightly more efficient than central composite design, but much more efficient than the three-level full factorial designs (Ferreira et al. 2007). For these reasons, Box-Behnken design was selected for this work.

In the present work, PHAs were obtained by Bacillus megaterium employing vinasse as carbon source. A statistical experimental design was applied to optimize the medium composition and fermentation conditions at laboratory scale. Synthesized biopolymers were extracted from the cells and characterized to evaluate their composition and thermal properties.

\section{Materials and methods Bacterial strain}

Fermentations for PHAs production were carried out with Bacillus megaterium (GenBank Database Accession Number: HM119600.1), named as BBST4. This strain, isolated from sediments of the Bahía Blanca Estuary, was identified and characterized by López et al. (2012). Bacillus megaterium was adapted to metabolize vinasse by several fermentations increasing gradually the vinasse concentration. Adapted bacteria were conserved at $-70{ }^{\circ} \mathrm{C}$ in vials containing $1 \mathrm{~mL}$ growth medium and $20 \%$ glycerol. The growth medium was composed of $10 \mathrm{~g} / \mathrm{L}$ vinasse, $10 \mathrm{~g} / \mathrm{L}$ yeast extract, and $5 \mathrm{~g} / \mathrm{L}$ peptone. Bacteria cells were reactivated at $30{ }^{\circ} \mathrm{C}$ for $24 \mathrm{~h}$ in the described growth medium. They were stored at $4{ }^{\circ} \mathrm{C}$ in slopes containing the growth medium and $20 \mathrm{~g} / \mathrm{L}$ agar. Fermentation inocula were prepared by transferring bacteria cells using a wire loop into a shake flask containing $50 \mathrm{~mL}$ of the growth medium that were cultivated at $30^{\circ} \mathrm{C}$ for $24 \mathrm{~h}$.

\section{Carbon source}

Vinasse, provided by a sugar-alcohol company located at Famaillá (Tucumán, Argentina), was used as carbon source. In Fig. 1 it is shown the flowchart of the bioethanol process from sugar cane. As it can be observed, vinasse is one of the byproducts resulting from this process. In this work, two vinasse samples called $\mathrm{V}_{2017}$ and $\mathrm{V}_{2018}$ were used.

Vinasse samples were physicochemically characterized by chemical oxygen demand (COD), biological oxygen demand (BOD), total organic carbon (TOC), total nitrogen $(\mathrm{TN})$ and $\mathrm{pH}$. Many of these studies were carried out at the Environmental Chemistry Laboratory, Universidad Nacional del Sur (Bahía Blanca, Argentina) by different standard methods: TOC was determined using a TOC analyzer (Exeter analytical CE440); TN by the Kjeldahl method (Bradstreet 1954); TSS by the Standard Method 2540 D (Total Suspended Solids Dried at $103-105{ }^{\circ} \mathrm{C}$ ); TFS and TVS by the Standard Method 2540 E (fixed and volatile solids ignited at $550{ }^{\circ} \mathrm{C}$ ), using the protocols described by Standard Methods for the examination of Water and Wastewater 20th Edition (Eaton et al. 1998); COD by the Standard Method Potassium Dichromate (Burke and Mavrodineanu 1977); and BOD using the Winkler method (Prambudy et al. 2019). The pH was measured using a Sensorex $\mathrm{pH}$ meter.

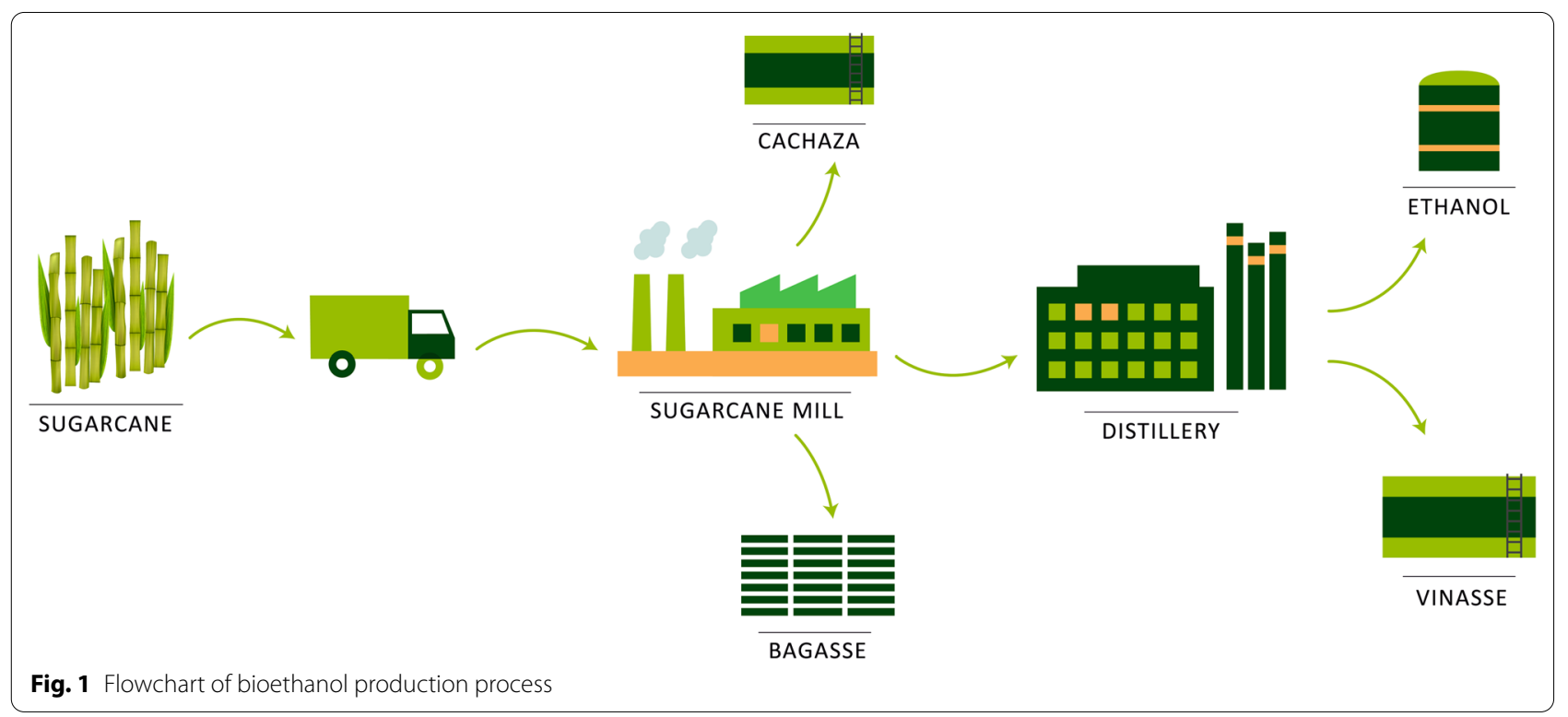




\section{Culture media}

The composition of the culture media was: $2.5 \mathrm{~g} / \mathrm{L}$ $\mathrm{MgSO}_{4} \cdot 7 \mathrm{H}_{2} \mathrm{O}, 2.5 \mathrm{~g} / \mathrm{L} \mathrm{NaCl}, 0.5 \mathrm{~g} / \mathrm{L} \mathrm{FeSO}_{4} \cdot 7 \mathrm{H}_{2} \mathrm{O}$, $0.05 \mathrm{~g} / \mathrm{L} \mathrm{MnSO}_{4} \cdot 4 \mathrm{H}_{2} \mathrm{O}$, vinasse, $\mathrm{NH}_{4} \mathrm{NO}_{3}$, and $\mathrm{K}_{2} \mathrm{HPO}_{4}$. Concentration of carbon, nitrogen, and phosphorous was achieved varying the quantities of vinasse, $\mathrm{NH}_{4} \mathrm{NO}_{3}$, and $\mathrm{K}_{2} \mathrm{HPO}_{4}$ added to the culture medium. The $\mathrm{pH}$ of the media was adjusted to 7.0 by adding dilute sodium hydroxide solution.

\section{Optimization of culture media composition and fermentation conditions}

For the optimization of culture media composition and fermentation conditions, a Box-Behnken experimental design and response surface methodology was employed.

To optimize the composition of the culture media, three independent variables were chosen: carbon $(C)$, nitrogen $(\mathrm{N})$, and phosphorus $(\mathrm{Ph})$ concentrations, which were prescribed into 3 levels code: $-1,0,1$ (Table 1 ). The ranges of the concentrations of $\mathrm{C}, \mathrm{N}$, and $\mathrm{Ph}$ were selected based on previous works (Acosta-Cárdenas et al. 2018; Wang et al. 2013; Berekaa and Al Thawadi 2012). The design matrix for 15 experiments is presented in Table 2. The response variable was PHB productivity (expressed in $\mathrm{mg} / \mathrm{L} \mathrm{h}$ ). In the experimental assays, cultures were incubated in 250-mL Erlenmeyer flasks, containing $100 \mathrm{~mL}$ of each culture medium given by the experimental design, at $30{ }^{\circ} \mathrm{C}$ for $24 \mathrm{~h}$ and $150 \mathrm{rpm}$ in an orbital shaker.

To complement the optimization of PHA production by $B$. megaterium and vinasse as carbon source, a second experimental design was carried out. As independent variables were chosen carbon/nitrogen ratio $(\mathrm{C} / \mathrm{N})$, temperature $(T)$, and time $(t)$ and they were prescribed into 3 levels code: $-1,0,1$ (Table 1 ). The ranges of $\mathrm{C} / \mathrm{N}$ ratios, $T$, and $t$ were selected based on previous works
Table 2 Factor values for independent variables and response variable (experimental and predicted) of screening experiments to optimize culture media composition

\begin{tabular}{lrrrll}
\hline Run & $\mathbf{C}(\mathbf{g} / \mathbf{L})$ & $\mathbf{N}(\mathbf{g} / \mathbf{L})$ & $\mathbf{P h}(\mathbf{g} / \mathbf{L})$ & $\begin{array}{l}\boldsymbol{P} \text {-experimental } \\
(\mathbf{m g} / \mathbf{L} \mathbf{h})\end{array}$ & $\begin{array}{l}\boldsymbol{P} \text {-predicted } \\
(\mathbf{m g} / \mathbf{L} \mathbf{h})\end{array}$ \\
\hline 1 & -1 & -1 & 0 & 1.75 & 1.80 \\
2 & 1 & -1 & 0 & 0.54 & 0.69 \\
3 & -1 & 1 & 0 & 0.59 & 0.60 \\
4 & 1 & 1 & 0 & 0.24 & 0.44 \\
5 & -1 & 0 & -1 & 0.25 & 0.64 \\
6 & 1 & 0 & -1 & 0.46 & 0.67 \\
7 & -1 & 0 & 1 & 1.29 & 1.24 \\
8 & 1 & 0 & 1 & 0.26 & 0.03 \\
9 & 0 & -1 & -1 & 1.55 & 1.33 \\
10 & 0 & 1 & -1 & 1.38 & 1.11 \\
11 & 0 & -1 & 1 & 1.52 & 1.77 \\
12 & 0 & 1 & 1 & 0.43 & 0.64 \\
13 & 0 & 0 & 0 & 0.27 & 0.29 \\
14 & 0 & 0 & 0 & 0.27 & 0.29 \\
15 & 0 & 0 & 0 & 0.32 & 0.29 \\
\hline
\end{tabular}

$C$ carbon; $N$ nitrogen; $P h$ phosphorous; $P$ PHB productivity

(Pal et al. 2009; Grothe et al. 1999). The design matrix for 15 experiments is presented in Table 3. As in the case of optimization of culture media, the response variable was $\mathrm{PHB}$ productivity. Cultures were incubated in $250-\mathrm{mL}$ Erlenmeyers, containing $100 \mathrm{~mL}$ of culture medium with different $\mathrm{C} / \mathrm{N}$ ratios at different temperatures and times, following the experimental design.

After all fermentation assays, culture medium was centrifuged for $10 \mathrm{~min}$ at $4000 \mathrm{rpm}$. Cell pellets were washed with distilled water 3 times and dried to constant weight at $60{ }^{\circ} \mathrm{C}$ in an oven with forced air circulation.

Table 1 Independent variables with their respective coded values and levels used in the Box-Behnken design

\begin{tabular}{|c|c|c|c|}
\hline \multicolumn{4}{|c|}{ Culture media composition } \\
\hline Level & $C(g / L)$ & $N(g / L)$ & $\mathrm{Ph}(\mathrm{g} / \mathrm{L})$ \\
\hline $\operatorname{High}(+1)$ & 8 & 0.4 & 1.2 \\
\hline Central (0) & 6 & 0.25 & 1.05 \\
\hline $\operatorname{Low}(-1)$ & 4 & 0.1 & 0.9 \\
\hline \multicolumn{4}{|c|}{ Fermentations conditions } \\
\hline Level & $\mathrm{C} / \mathrm{N}$ & $T\left({ }^{\circ} \mathrm{C}\right)$ & $t(\mathrm{~h})$ \\
\hline $\operatorname{High}(+1)$ & 40 & 37 & 72 \\
\hline Central (0) & 30 & 33.5 & 48 \\
\hline $\operatorname{Low}(-1)$ & 20 & 30 & 24 \\
\hline
\end{tabular}

C carbon; $N$ nitrogen; $P h$ phosphorous; $C / N$ carbon/nitrogen ratio; $T$ fermentation temperature; $t$ fermentation time 
Table 3 Factor values for independent variables and response variable (experimental and predicted) of screening experiments to optimize fermentation conditions

\begin{tabular}{lrrrrr}
\hline Run & $\mathbf{C} / \mathbf{N}$ & $\boldsymbol{T}\left({ }^{\circ} \mathbf{C}\right)$ & $\boldsymbol{t}(\mathbf{h})$ & $\begin{array}{l}\boldsymbol{P} \text {-experimental } \\
(\mathbf{m g} / \mathbf{L})\end{array}$ & $\begin{array}{l}\boldsymbol{P} \text {-predicted } \\
(\mathbf{m g} / \mathbf{L} \mathbf{~})\end{array}$ \\
\hline 1 & -1 & -1 & 0 & 5.1 & 5.3 \\
2 & 1 & -1 & 0 & 5.5 & 4.6 \\
3 & -1 & 1 & 0 & 4.4 & 5.3 \\
4 & 1 & 1 & 0 & 4.0 & 3.9 \\
5 & -1 & 0 & -1 & 9.7 & 9.9 \\
6 & 1 & 0 & -1 & 4.0 & 5.3 \\
7 & -1 & 0 & 1 & 3.0 & 1.8 \\
8 & 1 & 0 & 1 & 4.5 & 4.4 \\
9 & 0 & -1 & -1 & 10.3 & 10.0 \\
10 & 0 & 1 & -1 & 9.5 & 8.5 \\
11 & 0 & -1 & 1 & 3.2 & 4.3 \\
12 & 0 & 1 & 1 & 4.8 & 5.2 \\
13 & 0 & 0 & 0 & 6.9 & 6.6 \\
14 & 0 & 0 & 0 & 6.3 & 6.6 \\
15 & 0 & 0 & 0 & 6.5 & 6.6 \\
\hline
\end{tabular}

$C / N$ carbon/nitrogen ratio; $T$ fermentation temperature; $t$ fermentation time; $P$ PHB productivity

\section{Quantification of accumulated PHA}

Gas chromatography (GC) was used to quantify accumulated PHA. This technique specifically determines PHB. Samples for GC analysis were prepared as described by Riis and Mai (1988). Two mL of 1,2 dichloroethane, $2 \mathrm{~mL}$ propanol containing hydrochloric acid (1 volume concentrated hydrochloric acid +4 volume propanol) and $200 \mu \mathrm{L}$ of internal standard solution ( $2 \mathrm{~g}$ benzoic acid in $50 \mathrm{~mL}$ propanol) were added to $40 \mathrm{mg}$ of dry bacterial mass. Then, the sample was kept for $2 \mathrm{~h}$ in an incubator at $100{ }^{\circ} \mathrm{C}$. After cooling to room temperature, $4 \mathrm{~mL}$ of water were added, and the mixture was shaken for 20-30 s. The heavier phase was injected into a gas chromatograph Hewlett Packard 5890 (Series II).

To quantify $\mathrm{PHB}$, a calibration curve was previously performed by using a commercial PHB (Biomer, Germany). Productivity $(P)$ of $\mathrm{PHB}$ was calculated using Eq. 1:

$$
P=\frac{\mathrm{PHB}}{t V},
$$

where $P H B$ is the quantity of the biopolymer in milligrams, $t$ is the fermentation time in hours, and $V$ is the culture media volume in liters.

\section{PHA extraction}

Centrifuged cells were lyophilized in a Rificor, L-A-B3-C lyophilizer and PHA was extracted with chloroform in a Soxhlet apparatus during $48 \mathrm{~h}$. After extraction, solvent was removed by evaporation and PHA yield was calculated by Eq. 2:

$$
\mathrm{PHA}_{\text {yield }}=\frac{\mathrm{PHA}_{\text {extracted }}}{\text { Dry cell weight }} \times 100 \text {, }
$$

where PHA $_{\text {extracted }}$ corresponds to the PHA obtained after solvent extraction and dry cell weight is the amount of lyophilized cell used, both expressed in $\mathrm{g} / \mathrm{L}$.

\section{Characterization of extracted PHA Fourier-transform infrared (FTIR)}

FTIR analysis was performed using a spectrophotometer Nicolet Nexus. Samples were well-mixed with $\mathrm{KBr}$ (Sigma-Aldrich, 99\% purity) at 1\% w/w and press in order to obtain transparent discs. Spectra were obtained from 100 accumulated scans at $4 \mathrm{~cm}^{-1}$ resolution in the range $4000-400 \mathrm{~cm}^{-1}$.

\section{Scanning electron microscopy (SEM)}

Scanning electron microscopy (SEM) was conducted on a JEOL JSM-35CF electron microscope at an accelerating voltage of $10 \mathrm{kV}$. Samples were dispersed over $3 \mathrm{M}$ aluminum conductive tape stuck onto stubs by using an air flow and coated with gold in a sputter coater SPI.

\section{Differential scanning calorimetry (DSC)}

Thermal properties were evaluated by differential scanning calorimetry (DSC) using a Perkin-Elmer DSC calorimeter under nitrogen atmosphere. Analysis was carried out on $\sim 8 \mathrm{mg}$ of sample heating from 25 to $190{ }^{\circ} \mathrm{C}$, followed by a subsequent cooling down to $25^{\circ} \mathrm{C}$, and finally a second heating to $190{ }^{\circ} \mathrm{C}$. All thermal ramps were performed at a rate of $10{ }^{\circ} \mathrm{C} / \mathrm{min}$. Melting point $\left(T_{\mathrm{m}}\right)$ and melting enthalpy $\left(\Delta H_{\mathrm{m}}\right)$ were obtained from thermograms at the second heating stage.

\section{Thermogravimetric analysis (TGA)}

Thermal degradation was performed using a thermogravimetric balance Discovery TA Instruments. Samples $(\sim 8 \mathrm{mg})$ were heated from 25 to $700{ }^{\circ} \mathrm{C}$, under nitrogen atmosphere, at $10{ }^{\circ} \mathrm{C} / \mathrm{min}$. Mass-temperature curves were obtained and the first derivative was calculated. The peak of the first derivative indicates the maximum thermal degradation temperature $\left(T_{\mathrm{d}}\right)$, point of maximum rate of change on the mass curve. 
Table 4 Physicochemical properties of vinasse samples

\begin{tabular}{lll}
\hline Physicochemical property & \multicolumn{2}{l}{ Vinasse sample } \\
\cline { 2 - 3 } & $\mathbf{V}_{\mathbf{2 0 1 7}}$ & $\mathbf{V}_{\mathbf{2 0 1 8}}$ \\
\hline BOD $(\mathrm{mg} / \mathrm{L})$ & $96,500 \pm 500$ & $36,170 \pm 1808$ \\
$\mathrm{COD}(\mathrm{mg} / \mathrm{L})$ & $1,01,600 \pm 500$ & $40,880 \pm 822$ \\
$\mathrm{TN}(\mathrm{mg} / \mathrm{L})$ & $1100 \pm 20$ & $255 \pm 10$ \\
$\mathrm{TOC}(\mathrm{g} / \mathrm{L})$ & $40.5 \pm 0.5$ & $16.3 \pm 0.5$ \\
$\mathrm{pH}$ & 4.8 & 4.6 \\
\hline
\end{tabular}

$B O D$ biological oxygen demand; $C O D$ chemical oxygen demand; $T N$ total nitrogen; TOC total organic carbon

\section{Results and discussion Carbon source}

Vinasse samples were physicochemically characterized and results are shown in Table 4. As it can be observed, physicochemical parameters of both samples $\left(\mathrm{V}_{2017}\right.$ and $\mathrm{V}_{2018}$ ) were significantly different between them. This variability depends on the sugar cane variety and maturation, the substrate used in fermentation, distillation, and sulfitation process that enriches the downstream products with sulfur compounds especially sulfate species (Godoi et al. 2019). This wide range of physicochemical properties represents a challenge to use vinasse as carbon source on PHA production. Even though both studied vinasse samples contained raised BOD and COD levels and high suspended solids, $\mathrm{V}_{2017}$ presented significantly higher values than $\mathrm{V}_{2018}$. These parameters are responsible for the difficult disposal and are according to the average values found in the literature (Acosta-Cárdenas et al. 2018; Carrilho et al. 2016; Nakashima and Oliveira 2020). TN content of $V_{2017}$ was 4.3 times higher than the corresponding to $\mathrm{V}_{2018}$. In the bibliography it was found $\mathrm{TN}$ values goes from $60 \mathrm{mg} / \mathrm{L}$ (Zanfonato et al. 2018) to $587 \mathrm{mg} / \mathrm{L}$ (Popolizio 2017), demonstrating once again the variability of this by-product and the challenge when using it as carbon source to produce biopolymers via microbial fermentation. Regarding TOC content, the value corresponding to $\mathrm{V}_{2018}$ was about half of the content obtained for the $\mathrm{V}_{2017}$ sample. Parsaee et al. (2019) reported a TOC value of $20.16 \mathrm{~g} / \mathrm{L}$, similar to the value obtained for $\mathrm{V}_{2018}$. On the other hand, Fagier et al. (2018) obtained a TOC value of $48 \mathrm{~g} / \mathrm{L}$, similar to the value obtained for $\mathrm{V}_{2017} \cdot \mathrm{pH}$ values of vinasse samples are in the range reported on the bibliography (Fukushima et al. 2019). These low values hinder the disposal of this by-product.

\section{Optimization of culture media composition} and fermentation conditions

In this study, Bacillus megaterium was employed to synthesize biopolymers via microbial fermentation. According to López et al. (2012) and Porras et al. (2017), this strain is capable of producing PHB and PHA copolymers, respectively. To optimize culture media composition 15 experiments, given by the Box-Behnken experimental design, were carried out and obtained PHB productivity $(P)$ values and predicted responses are included in Table 2. The vinasse sample employed in these assays as carbon source was $\mathrm{V}_{2017}$. The influence of the different tested independent variables (carbon, nitrogen, and phosphorus concentration) on the biopolymer productivity are given by the $p$ value: those that presented $p<0.05$ significantly affected the response parameter, meanwhile variables that showed $p>0.05$ were considered not statistically significant.

$p$ values for the three independent variables and their interactions are given in Table 5 . It is important to note that not all variables affected the productivity in the same way. It can be seen that $\mathrm{C}$ and $\mathrm{N}$ statistically influenced PHB productivity, considering a significance level of 0.05 ( $p=0.0441$ and 0.0280 , respectively). On the other hand, phosphorus concentration was not statistically significant ( $p=0.8941)$. Interactions between studied variables were not remarkable on $\mathrm{PHB}$ productivity, except the quadratic term $N^{2}(p=0.0167)$.

For predicting the optimal culture media composition, a polynomial function was fitted to the experimental data (Eq. 3):

$$
\begin{aligned}
P= & 0.286-0.296 \mathrm{C}-0.338 \mathrm{~N}-0.010 \mathrm{Ph} \\
& -0.080 \mathrm{C}^{2}+0.213 \mathrm{CN}-0.310 \mathrm{CPh} \\
& +0.570 \mathrm{~N}^{2}-0.228 \mathrm{NPh}+0.357 \mathrm{Ph}^{2}
\end{aligned}
$$

where $P$ is $\mathrm{PHB}$ productivity $(\mathrm{mg} / \mathrm{L} \mathrm{h})$, meanwhile $\mathrm{C}, \mathrm{N}$, $\mathrm{Ph}$ represents the carbon, nitrogen, and phosphorus concentration $(\mathrm{mg} / \mathrm{L})$ in the culture media.

This polynomial function represents a good fit of experimental data since the determination coefficient

Table 5 Coefficient and $p$ values for independent variables and their interactions, obtained from optimization of culture media composition

\begin{tabular}{lcc}
\hline Variable & Coefficient & $\boldsymbol{p}$ value \\
\hline $\mathrm{C}$ & -0.2956 & 0.044 \\
$\mathrm{~N}$ & -0.3384 & 0.028 \\
$\mathrm{Ph}$ & -0.0155 & 0.894 \\
$\mathrm{C}^{2}$ & -0.0783 & 0.651 \\
$\mathrm{C}-\mathrm{N}$ & 0.2130 & 0.231 \\
$\mathrm{C}-\mathrm{Ph}$ & -0.3106 & 0.104 \\
$\mathrm{~N}^{2}$ & 0.5745 & 0.017 \\
$\mathrm{~N}-\mathrm{Ph}$ & -0.2287 & 0.203 \\
$\mathrm{Ph}^{2}$ & 0.3570 & 0.080 \\
\hline
\end{tabular}

C carbon; $N$ nitrogen; $P h$ phosphorous 
$\left(R^{2}\right)$ was 0.8924 . According to Nygaard et al. (2019), the model has a high correlation because $R^{2}$ is in the range of $0.7-0.9$. $\mathrm{C}$ and $\mathrm{N}$ variables have similar negative standardized coefficients $(-0.296$ and -0.338 , respectively). The fact that these coefficients were negative means that PHB productivity decreased when $\mathrm{C}$ or $\mathrm{N}$ concentration were increased. Even though the coefficient of $\mathrm{Ph}$ was also negative, it was very low $(-0.010)$, indicating that the effect of this variable on PHB productivity was not significant. Quadratic terms are model fit coefficients which demonstrate that there is a curvature and a local optimum point could be found. Thus, the optimum level for each studied variable, estimated from the maximum point of the polynomial PHB model, was estimated using the solver function of Statgraphics Centurion XV.II X64 tools. Optimum level of $\mathrm{C}, \mathrm{N}$, and $\mathrm{Ph}$ were $-1,-1$ and 0.935, respectively. Comparison with data found in the bibliography is difficult because several factors should be taken into account to analyze the effect of these variables on PHB productivity. For example, Bora (2013) studied the PHA synthesis by Bacillus megaterium, using fructose as carbon source, and $\mathrm{K}_{2} \mathrm{HPO}_{4}$ and $\mathrm{Na}_{2} \mathrm{HPO}_{4}$ as phosphorus sources. This author reported that fructose and its interaction with $\mathrm{Na}_{2} \mathrm{HPO}_{4}$ significantly affected PHB productivity. On the other hand, Nygaard et al. (2019) carried out fermentations for PHA production using Cupriavidus necator, and evaluated the effect of carbon, nitrogen and phosphorus concentration, as well as medium $\mathrm{pH}$ on the biopolymer productivity. Obtained results showed that productivity was statistically affected by $\mathrm{N}, \mathrm{pH}$, and $\mathrm{C}^{2}$. These examples from the literature demonstrate that the effect of fermentation variables on PHA productivity depends on many factors such as strain, nutrient sources, and fermentation conditions, among others. Therefore, the comparison with results obtained in this work is not suitable.

As it was aforementioned, phosphorus concentration did not have a significant effect on PHB productivity, so the response surface was built taking into account only carbon and nitrogen concentrations as independent parameters and the productivity as response variable (Fig. 2). These response surface plots reinforced the discussed results about the effect of $\mathrm{C}$ and $\mathrm{N}$ concentrations on PHB productivity. As can be seen, productivity increased when the carbon and nitrogen concentration decreased. This could be attributed to the fact that vinasse contains phenolic compounds, difficult to be biologically degraded by bacteria, that have antimicrobial and phytotoxic properties (Parsaee et al. 2019). Besides, the decrease in PHB productivity by increasing nitrogen concentration may be due to that Bacillus $\mathrm{sp}$. bacteria require the limitation of this nutrient for the production of PHB as metabolite (Kanekar et al. 2015).

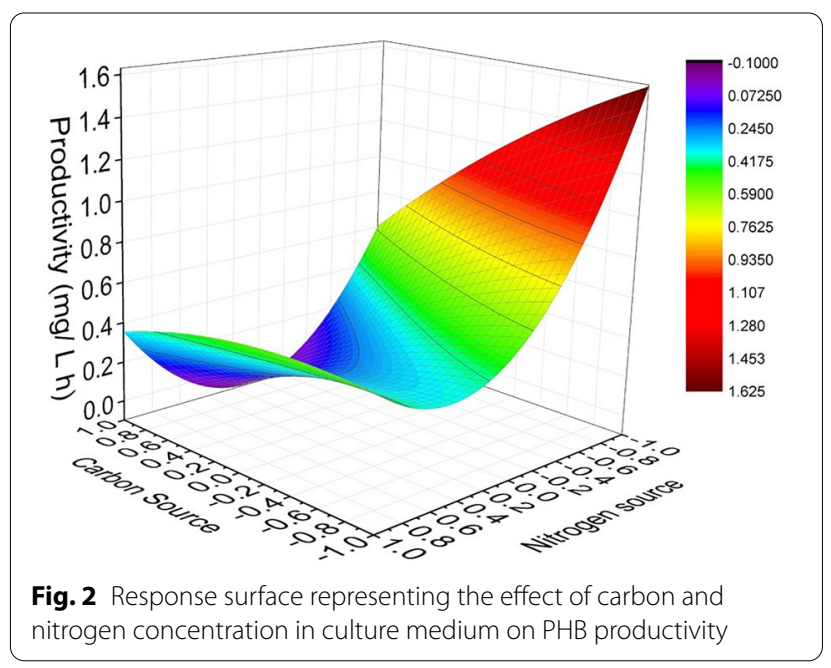

Table 6 Coefficient and $p$ values for independent variables and their interactions, obtained from optimization of fermentation conditions

\begin{tabular}{lcl}
\hline Variable & Coefficient & $\boldsymbol{p}$ value \\
\hline $\mathrm{C} / \mathrm{N}$ & -0.5340 & 0.278 \\
$T$ & -0.1878 & 0.702 \\
$t$ & -2.2338 & 0.003 \\
$\mathrm{C} / \mathrm{N}-\mathrm{T}$ & -0.1580 & 0.756 \\
$\mathrm{C} / \mathrm{N}-t$ & 1.8160 & 0.032 \\
$T-t$ & 0.6016 & 0.370 \\
$(\mathrm{C} / \mathrm{N})^{2}$ & -1.7675 & 0.495 \\
$T^{2}$ & -0.0898 & 0.901 \\
$t^{2}$ & 0.4981 & 0.495 \\
\hline
\end{tabular}

$C / N$ carbon/nitrogen ratio; $T$ fermentation temperature; $t$ fermentation time

From the optimum levels, PHB maximum productivity was calculated obtaining a value of $2.43 \mathrm{mg} / \mathrm{L} \mathrm{h}$. This is a low productivity compared to values found in the literature. For example, Bhattacharyya et al.(2012) reported a PHB productivity of $0.21 \mathrm{~g} / \mathrm{L} \mathrm{h}$ employing vinasse as carbon source and Haloferax mediterranei as strain. Therefore, to improve PHB productivity by $B$. megaterium employing vinasse as carbon source, an additional experimental design was carried out to optimize the $\mathrm{C} / \mathrm{N}$ ratio and growing conditions (fermentation time and temperature). Therefore, 15 experiments given by the Box-Behnken experimental design were done and $\mathrm{PHB}$ productivity $(P)$ values and predicted responses obtained are included in Table 3 . The vinasse sample employed in these assays as carbon source was $\mathrm{V}_{2018}$. The $p$ value for the three variables and their interactions are given in Table 6. Taking into account the different independent variables, fermentation time had a statistically significant effect on PHB productivity ( $p=0.0034)$. Meanwhile, 
fermentation temperature and $\mathrm{C} / \mathrm{N}$ ratio did not significantly affect $\mathrm{PHB}$ productivity by $B$. megaterium ( $p$ $=0.7016$ and 0.2777 , respectively). Regarding the interaction between the variables, the only one that had a notable influence on PHB productivity was the one between $\mathrm{C} / \mathrm{N}$ and time (0.0318), probably due to the significant effect of fermentation time. None of the quadratic terms were statistically significant. Equation 4 described the polynomial model which was a good fit to the experimental data with a determination coefficient $\left(R^{2}\right)$ of 0.9093 :

$$
\begin{aligned}
P= & 6.57-0.524 C / N-0.175 T-2.25 t \\
& -1.7 C / N^{2}-0.2 C / N . T+1.8 C / N . t \\
& -0.08 T^{2}+0.6 T . t+0.5 t^{2},
\end{aligned}
$$

where $P$ is the PHB productivity $(\mathrm{mg} / \mathrm{L} \mathrm{h}), t$ is the fermentation time (h), and $T$ is the fermentation temperature $\left({ }^{\circ} \mathrm{C}\right)$.

The time variable had the largest negative standardized coefficient $(-2.25)$, indicating that an increase in the fermentation time led to a decrease in PHB productivity. The longer the fermentation time the lower the productivity. This tendency is in good agreement with the low PHB production rate, not accumulating more PHB until the end of the cultivation. Similar behavior was reported by Dalsasso et al. (2019) studying PHB production by Cupriavidus necator using a blend of vinasse and sugarcane molasses as substrate. On the other hand, coefficients of $\mathrm{C} / \mathrm{N}$ and $T$ variables presented very low values, demonstrating that they had no significant effect on the response variable. The quadratic coefficients and those of the interactions between variables resulted negligible, except the one corresponding to $\mathrm{C} / \mathrm{N}$ and $t$ interaction, mainly attributed to the effect of the fermentation time. Figure 3 shows the three response surface plots representing the productivity as response variable and $\mathrm{C} / \mathrm{N}$ ratio and fermentation time (Fig. 3a), temperature and fermentation time (Fig. 3b), and $\mathrm{C} / \mathrm{N}$ and temperature (Fig. 3c) as independent variables. The only significant interaction was between $\mathrm{C} / \mathrm{N}$ and $t$; when $t$ value was minimal and the ratio $\mathrm{C} / \mathrm{N}$ increased, the production of PHB increased. Besides, when $t$ reached its highest value, the slope of PHB production as a function of $\mathrm{C} / \mathrm{N}$ became negative (Fig. 3a). The factor associated with the quadratic contribution of $\mathrm{C} / \mathrm{N}$ presented its maximum value in the vicinity of the central point. Thus, the maximum $\mathrm{PHB}$ production occurred when $\mathrm{C} / \mathrm{N}$ had a value of 23.95 (Fig. 3a, c). As it can be seen, the temperature range assayed in these experiences did not significantly affect the PHB productivity (Fig. 3b, c), despite these values being within the optimal growing temperature range for this strain (Porras et al. 2017).

The optimal value of $\mathrm{C} / \mathrm{N}$ ratio, fermentation time and temperature to produce PHB by $B$. megaterium and vinasse as carbon source were $24.01,30.25{ }^{\circ} \mathrm{C}$ and $24 \mathrm{~h}$. The optimal productivity value in this case, predicted by the model, was $10.6 \mathrm{mg} / \mathrm{L} \mathrm{h}$. In order to verify the good correlation of the model, fermentations was carried out under these optimal conditions that theoretically maximize the PHB productivity and the experimental value resulted being $9.7 \mathrm{mg} / \mathrm{L} \mathrm{h}$. Thus, the effectiveness of the model was demonstrated since both values are similar with the same magnitude order. Pramanik et al. (2012) reported a similar PHB productivity $(0.015 \mathrm{~g} / \mathrm{L} \mathrm{h})$ using a culture medium with $10 \%$ raw vinasse as carbon source and Haloarcula marismortui as strain. Otherwise, reported values of PHB production by Bacillus megaterium by other authors are very variable according to the carbon source used. Jimenez (2011) informed a PHB productivity of $0.082 \mathrm{~g} / \mathrm{L} \mathrm{h}$ from glucose as carbon source, Obruca et al. (2011) reported a value of $0.056 \mathrm{~g} / \mathrm{L} \mathrm{h}$ employing cheese whey, and Porras (2012) obtained a PHB productivity of $0.0125 \mathrm{~g} / \mathrm{L} \mathrm{h}$ using starch.

As it was aforementioned, vinasse sample employed in the optimization of the media composition was $\mathrm{V}_{2017}$; meanwhile for the optimization of growing conditions, $\mathrm{V}_{2018}$ was employed. The variability in physicochemical properties of both vinasse samples led to significant differences in PHB productivity. As it can be seen, the best values were obtained using $\mathrm{V}_{2018}$ in the second experimental design. When $\mathrm{V}_{2018}$ was employed, it reached a productivity 4.4 times higher than value obtained with $\mathrm{V}_{2017}$, estimated for the optimal conditions. This difference could be associated with the higher BOD and COD values of $\mathrm{V}_{2017}$ than those of $\mathrm{V}_{2018}$. Particularly, BOD high values indicate that microorganisms need more oxygen to degrade it (Porras 2012) and this issue could affect the PHB production by B. megaterium from $\mathrm{V}_{2017}$.

\section{PHA extraction and characterization}

Fermentations were carried out using the optimal composition. PHB was extracted and a characterization was done. Considering the mass of dry cells and extracted PHA, a polymer yield of $37 \%$ was obtaining. Valappil et al. (2007) reported a similar value for PHA yield (31\%), using glucose as substrate and Bacillus cereus as microorganism. On the other hand, using vinasse as carbon source, Pramanik et al.(2012) obtained a PHA yield 

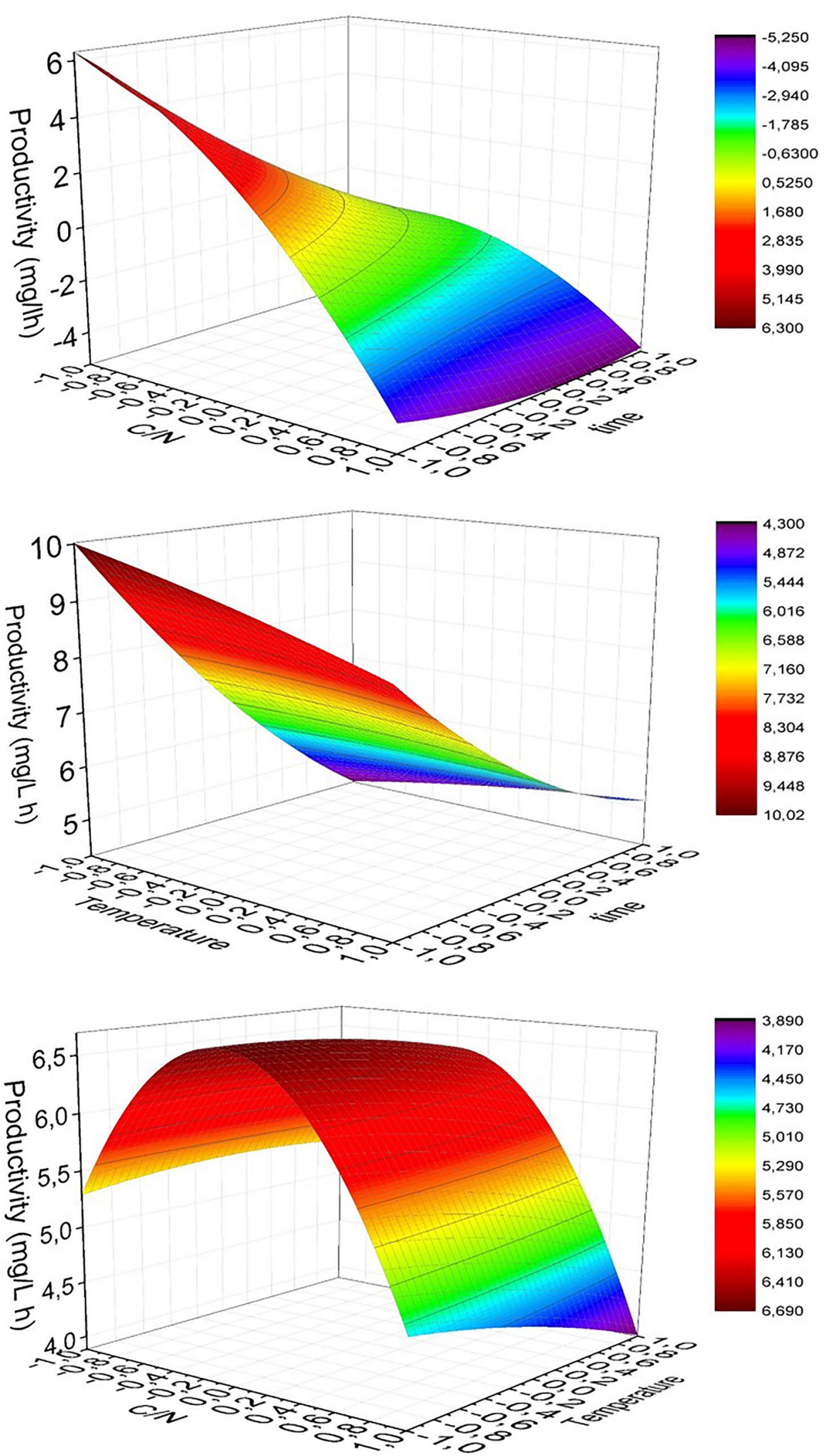

Fig. 3 (See legend on previous page.) 
of $23 \%$ employing Haloarcula marismortui as strain and Zanfonato et al.(2018) reported a maximum PHA yield of $26 \%$ with Cupriavidus necator. In addition, Bacillus sp. accumulated 75.5\% (Das et al. 2018), 54.6\% (Mohanrasu et al. 2020) and 59\% (Jimenez 2011) PHA using cheese whey in the first case and glucose in the others, respectively.

FTIR spectra of synthesized PHA are shown in Fig. 4 and it is in consonance with the PHB structure reported in the bibliography. A high intense band at $1726 \mathrm{~cm}^{-1}$ was observed which corresponds to the $\mathrm{C}=\mathrm{O}$ stretch of the ester group (Lathwal et al. 2018). Absorption band at $1455 \mathrm{~cm}^{-1}$ is attributed to the asymmetric deformation of $\mathrm{C}-\mathrm{H}$ bonds in $-\mathrm{CH}_{2}$ groups, while the band at $1380 \mathrm{~cm}^{-1}$ is assigned to the symmetric vibration of $\mathrm{CH}_{3}$ groups. The band at $1230 \mathrm{~cm}^{-1}$ is assigned to $\mathrm{CH}_{2}$ vibrations (Jimenez 2011).

Figure 4 also includes a SEM micrograph of the extracted biopolymer, showing the morphology of PHA granules. The microstructure gives a fairly porous material with fine grains interconnected and a strong tendency to form multigrain agglomerates. The morphology shows grains that are pseudo-spherical in shape with fairly uniform distribution. Similar observations were reported by Nwinyi and Owolabi (2019). They used microbial species obtained from an abattoir employing different carbon sources (acetate and molasses) in the mineral medium.

The melting temperature of obtained PHB was taken at the maximum of the endothermic peak in the DSC second heating thermogram. A value of $177.7^{\circ} \mathrm{C}$ was obtained which is in good agreement with values reported by Pradhan et al. (2018). These authors reported values of $175{ }^{\circ} \mathrm{C}$ and $176{ }^{\circ} \mathrm{C}$ for PHA obtained by Bacillus megaterium and Cupriavidus necator, respectively. The melting enthalpy determined of the PHA obtained in this study was $79.6 \mathrm{~J} / \mathrm{g}$. Pradhan et al.(2018) using B. megaterium and fructose as carbon source reported a melting enthalpy of $33 \mathrm{~J} / \mathrm{g}$ and Ansari and Fatma (2016) obtained $83.2 \mathrm{~J} / \mathrm{g}$ by Nostoc muscorum NCCU-442 and glucose as carbon source.

TGA was performed to detect the thermal stability of PHA. The maximum degradation temperature for the PHA synthesized was determined using the first derivative of thermogravimetric curve. PHA degradation occurred in two stages: in the first step, the degradation started at $225^{\circ} \mathrm{C}$ and extended until $300^{\circ} \mathrm{C}$ with a maximum degradation occurring at $255^{\circ} \mathrm{C}$ and the second step began after $310{ }^{\circ} \mathrm{C}$ and the maximum degradation took place at $325{ }^{\circ} \mathrm{C}$. The degradation in more than one stage was reported by various authors (Pradhan et al. 2018; Hassan et al. 2016; Liu et al. 2014). Particularly, Hassan et al. (2016) showed that PHB from Bacillus sp. was decomposed in 3 stages and resisted until $320^{\circ} \mathrm{C}$.

\section{Conclusions}

A medium was optimized to maximize PHA production with vinasse as carbon source. It was possible to determine the optimal culture medium composition and operating conditions. Vinasse composition had an important effect on productivity. FTIR spectrum, SEM micrography and melting temperature of extracted biopolymer are in good agreement with values reported in the literature.

This study demonstrated the successful utilization of vinasse for PHB production by Bacillus megaterium at the shake-flask level. Although promising at the

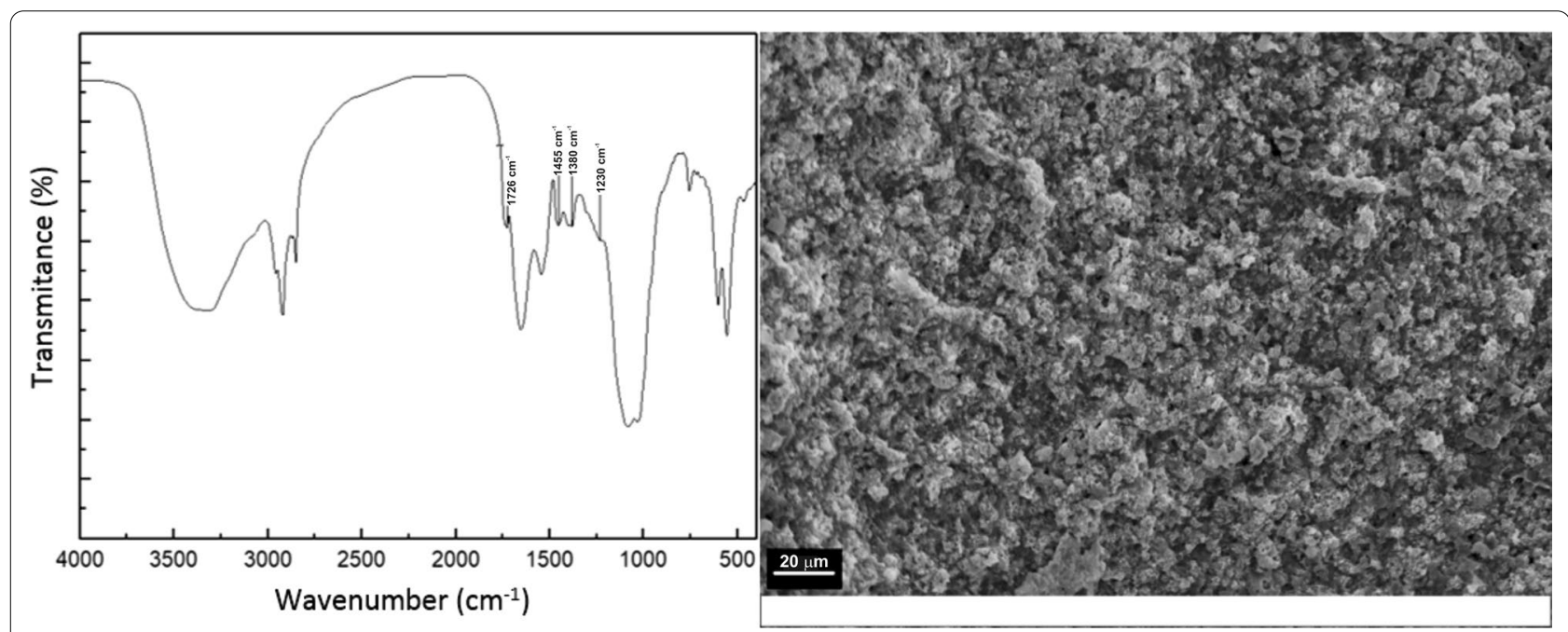

Fig. 4 SEM micrograph and FTIR spectrum of PHA synthesized by B. megaterium using vinasse as carbon source 
laboratory level, scaled-up fermentation studies with better controlled conditions (mainly $\mathrm{pH}$ and dissolved oxygen) can provide further insight into the functional feasibility of PHA production from vinasse.

\begin{abstract}
Abbreviations
PHA: Poly(hydroxyalcanoate)s; COD: Chemical oxygen demand; BOD: Biological oxygen demand; TOC: Total organic carbon; TN: Total nitrogen; C: Carbon concentration; N: Nitrogen concentration; Ph: Phosphorus concentration; GC: Gas chromatography; PHB: Poly(3-hydroxybutyrate); P: Productivity; C/N: Carbon/nitrogen ratio; T: Temperature; $t$ : Fermentation time; FTIR: Fouriertransform infrared spectroscopy; SEM: Scanning electron microscopy; DSC: Differential scanning calorimetry; TGA: Thermogravimetric analysis; $T_{d}$ : Thermal degradation temperature.
\end{abstract}

\section{Acknowledgements}

We express our gratitude to Consejo Nacional de Investigaciones Científicas y Técnicas, Agencia Nacional de Promoción Científica y Tecnológica, and Universidad Nacional del Sur for their financial support.

\section{Authors' contributions}

DT designed and performed experiments to optimize culture media and fermentation conditions using vinasse to PHA production, collected and analyzed data, and drafted the manuscript. OV helped to perform and collect data to characterize the extracted PHA, as well as supervised and revised the manuscript. MV designed and supervised the entire work, as well as drafted and revised the manuscript. All authors read and approved the final manuscript.

\section{Funding}

This work was financed by Consejo Nacional de Investigaciones Científicas y Técnicas (Grant Number: PIP 112-201501-00127), Agencia Nacional de Promoción Científica y Tecnológica (Grant Number: PICT-2014-2410).

\section{Availability of data and materials}

All data generated or analyzed during this study are included in the manuscript.

\section{Declarations}

\section{Ethics approval and consent to participate}

Not applicable.

\section{Consent for publication}

Not applicable.

\section{Competing interests}

The authors declare that they have no competing interests.

\author{
Author details \\ ${ }^{1}$ Planta Piloto de Ingeniería Química, PLAPIQUI (UNS-CONICET), Camino La \\ Carrindanga Km. 7, 8000 Bahía Blanca, Argentina. ²Departamento de Ingenie- \\ ría Química, Universidad Nacional del Sur, Av. Alem 1253, 8000 Bahía Blanca, \\ Argentina. ${ }^{3}$ Departamento de Química, Universidad Nacional del Sur, Av. Alem \\ 1253, 8000 Bahía Blanca, Argentina. \\ Received: 18 August 2021 Accepted: 1 December 2021 \\ Published online: 17 December 2021

\section{References} \\ Acosta-Cárdenas A, Alcaraz-zapata W, Cardona-Betancur M (2018) Sugarcane \\ molasses and vinasse as a substrate for polyhydroxyalkanoates (PHA) \\ production. Melazas y vinaza de la caña de azúcar como sustrato para \\ la producción de polihidroxialcanoatos (PHA). RevistasUnalEduCo \\ 85:220-225
}

Alsafadi D, Al-Mashaqbeh O (2017) A one-stage cultivation process for the production of poly-3-(hydroxybutyrate-co-hydroxyvalerate) from olive mill wastewater by Haloferax mediterranei. New Biotechnol 34:47-53. https://doi.org/10.1016/j.nbt.2016.05.003

Amini M, Yousefi-massumabad H, Younesi H, Abyar H (2020) Production of the polyhydroxyalkanoate biopolymer by Cupriavidus necator using beer brewery wastewater containing maltose as a primary carbon source. J Environ Chem Eng 8:103588. https://doi.org/10.1016/j.jece.2019.103588 Andrady AL (2015) Persistence of plastic litter in the oceans. In: Bergmann M Gutow L, Klages M (eds) Marine anthropogenic litter. Springer, Cham, pp 57-72

Anjum A, Zuber M, Zia KM et al (2016) Microbial production of polyhydroxyalkanoates (PHAs) and its copolymers : a review of recent advancements. Int J Biol Macromol 89:161-174. https://doi.org/10.1016/j.ijbiomac.2016. 04.069

Ansari S, Fatma T (2016) Cyanobacterial polyhydroxybutyrate (PHB): screening, optimization and characterization. PLoS ONE 11:1-20. https://doi.org/10. 1371/journal.pone.0158168

Berekaa M, Al Thawadi A (2012) Biosynthesis of polyhydroxybutyrate (PHB) biopolymer by Bacillus megaterium SW1-2. Application of Box-Behnken design for optimization of process parameters. Afr J Microbiol Res 6:2101-2108. https://doi.org/10.5897/ajmr11.1382

Bhattacharyya A, Pramanik A, Mitra A et al (2012) Utilization of vinasse for the production of polyhydroxybutyrate by Haloarcula marismortui. Folia Microbiol 57:71-79. https://doi.org/10.1007/s12223-011-0092-3

Bora L (2013) Polyhydroxybutyrate accumulation in Bacillus megaterium and optimization of process parameters using response surface methodology. J Polym Environ 21:415-420. https://doi.org/10.1007/ s10924-012-0529-z

Bradstreet RB (1954) Kjeldahl method for organic nitrogen. Anal Chem 26:185-187. https://doi.org/10.1021/ac60085a028

Burke RW, Mavrodineanu R (1977) Certification and use of acidic potassium dichromate solutions as an ultraviolet absorbance standard SRM 935. Dept. of Commerce, National Bureau of Standards, Washington

Carrilho ENVM, Labuto G, Kamogawa MY (2016) Destination of vinasse, a residue from alcohol industry: resource recovery and prevention of pollution. Environmental materials and waste: resource recovery and pollution prevention. Elsevier, Amsterdam. https://doi.org/10.1016/b978-0-12803837-6.00002-0

Dalsasso RR, Pavan FA, Bordignon SE et al (2019) Polyhydroxybutyrate (PHB) production by Cupriavidus necator from sugarcane vinasse and molasses as mixed substrate. Process Biochem 85:12-18. https://doi.org/10.1016/j. procbio.2019.07.007

Das S, Majumder A, Shukla V et al (2018) Biosynthesis of Poly(3-hydroxybutyrate) from Cheese Whey by Bacillus megaterium NCIM 5472. J Polym Environ 26:4176-4187. https://doi.org/10.1007/s10924-018-1288-2

de Godoi LAG, Camiloti PR, Bernardes AN et al (2019) Seasonal variation of the organic and inorganic composition of sugarcane vinasse: main implications for its environmental uses. Environ Sci Pollut Res 26:29267-29282. https://doi.org/10.1007/s11356-019-06019-8

Eaton AD, Clesceri LS, Greenberg AE, Franson MAH (1998) Standard methods for the examination of water and wastewater, 20th edn. American P, Washington

Fabra MJ, López-rubio A, Ambrosio-martín J, Lagaron JM (2016) Improving the barrier properties of thermoplastic corn starch-based films containing bacterial cellulose nanowhiskers by means of PHA electrospun coatings of interest in food packaging. Food Hydrocoll 61:261-268. https://doi. org/10.1016/j.foodhyd.2016.05.025

Fagier MA, Elmugdad AA, Aziz ME, Gabra NM (2018) Characterization of sugarcane vinasse. J Fac Sci Int Univ Afr. https://doi.org/10.21203/rs.3. rs-801030/v1

Ferreira SLC, Bruns H, Ferreira HS et al (2007) Box-Behnken design: an alternative for the optimization of analytical methods. Anal Chim Acta 597:179-186. https://doi.org/10.1016/j.aca.2007.07.011

Fukushima NA, Palacios-Bereche MC, Palacios-Bereche R, Nebra SA (2019) Energy analysis of the ethanol industry considering vinasse concentration and incineration. Renew Energy 142:96-109. https://doi.org/10. 1016/j.renene.2019.04.085

Grothe E, Moo-young M, Chisti Y (1999) Fermentation optimization for the production of poly ( $\beta$-hydroxybutyric acid) microbial thermoplastic. Enzyme Microb Technol 25:132-141 
Hassan MA, Bakhiet EK, Ali SG, Hussien HR (2016) Production and characterization of polyhydroxybutyrate (PHB) produced by Bacillus sp. isolated from Egypt. J Appl Pharm Sci 6:46-51. https://doi.org/10.7324/JAPS.2016. 60406

Jimenez JAL (2011) Biopolímeros de interés industrial. Síntesis y caracterización de polyhidroxibutirato (PHB). Dissertation. Universidad Nacional del Sur, Bahía Blanca

Kanekar PP, Kulkarni SO, Nilegaonkar SS, Sarnaik SS, Kshirsagar PR, Ponraj M, Kanekar SP (2015) Polymers for packaging applications. In: Alavi S, Thomas S, Sandeep KP, Kalarikkal N, Varghese JYS (eds) Polymers for packaging applications. Apple Academic Press, Florida, pp 197-225

Kaur L, Khajuria R, Parihar L, Singh GD (2017) Polyhydroxyalkanoates: biosynthesis to commercial production. J Microbiol Biotechnol Food Sci 6(4):1098-1106. https://doi.org/10.15414/jmbfs.2017.6.4.1098-1106

Koller M (2018) Biodegradable and biocompatible polyhydroxy-alkanoates (PHA): auspicious microbial macromolecules for pharmaceutical and therapeutic applications. Molecules 23:362. https://doi.org/10.3390/ molecules23020362

Kourmentza C, PI J, Venetsaneas N et al (2017) Recent advances and challenges towards sustainable polyhydroxyalkanoate (PHA) production. Bioengineering 2017:1-43. https://doi.org/10.3390/bioengineering4020055

Kovalcik A, Obruca S, Marova I (2019) Polyhydroxyalkanoates: their importance and future. BioResources 14:2468-2471

Lathwal P, Nehra K, Singh M, Rana JS (2018) Characterization of novel and efficient poly-3-hydroxybutyrate (PHB) producing bacteria isolated from rhizospheric soils. J Polym Environ 26:3437-3450. https://doi.org/10.1007/ s10924-018-1224-5

Liu Y, Huang S, Zhang Y, Xu F (2014) Isolation and characterization of a thermophilic Bacillus shackletonii $\mathrm{K} 5$ from a biotrickling filter for the production of polyhydroxybutyrate. J Environ Sci 26:1453-1462. https://doi.org/10. 1016/j.jes.2014.05.011

López JA, Naranjo JM, Higuita JC et al (2012) Biosynthesis of PHB from a new isolated Bacillus megaterium strain : outlook on future developments with endospore forming bacteria. Biotechnol Bioprocess Eng 17:250-258. https://doi.org/10.1007//s12257-011-0448-1

Mohanrasu K, Rao RGR, Dinesh GH et al (2020) Optimization of media components and culture conditions for polyhydroxyalkanoates production by Bacillus megaterium. Fuel 271:117522. https://doi.org/10.1016/j.fuel.2020. 117522

Nakashima RN, de Oliveira JS (2020) Comparative exergy assessment of vinasse disposal alternatives: concentration, anaerobic digestion and fertirrigation. Renew Energy 147:1969-1978. https://doi.org/10.1016/j. renene.2019.09.124

Nielsen C, Rahman A, Rehman AU et al (2017) Food waste conversion to microbial polyhydroxyalkanoates. Microb Biotechnol 10:1338-1352. https://doi.org/10.1111/1751-7915.12776

Nor NM, Mohamed MS, Loh TC et al (2017) Comparative analyses on medium optimization using one-factor-at-a-time, response surface methodology, and artificial neural network for lysine - methionine biosynthesis by Pediococcus pentosaceus RF-1. Biotechnol Biotechnol Equip 31:935-947. https://doi.org/10.1080/13102818.2017.1335177

Nwinyi OC, Owolabi TA (2019) Scanning electron microscopy and Fourier transmission analysis of polyhydroxyalkanoates isolated from bacteria species from abattoir in Ota, Nigeria. J King Saud Univ Sci 31:285-298. https://doi.org/10.1016/j.jksus.2017.08.003

Nygaard D, Yashchuk O, Hermida ÉB (2019) Evaluation of culture medium on poly(3-hydroxybutyrate) production by Cupriavidus necator ATCC 17697: application of the response surface methodology. Heliyon 5(3):e01353. https://doi.org/10.1016/j.heliyon.2019.e01374

Obruca S, Marova I, Melusova S, Mravcova L (2011) Production of polyhydroxyalkanoates from cheese whey employing Bacillus megaterium CCM 2037. Ann Microbiol 61:947-953. https://doi.org/10.1007/s13213-011-0218-5

Pais J, Serafim LS, Freitas F, Reis MAM (2016) Conversion of cheese whey into poly(3-hydroxybutyrate-co-3-hydroxyvalerate) by Haloferax mediterranei. N Biotechnol 33:224-230. https://doi.org/10.1016/j.nbt.2015.06.001

Pal A, Prabhu A, Kumar A et al (2009) Optimization of process parameters for maximum Poly( $\beta$-hydroxybutyrate) (PHB) production by Bacillus thuringiensis IAM 12077. Pol J Microbiol 58:149-154

Parsaee M, Kiani M, Kiani D, Karimi K (2019) A review of biogas production from sugarcane vinasse. Biomass Bioenerg 122:117-125. https://doi.org/10. 1016/j.biombioe.2019.01.034
Popolizio DAT (2017) Efecto de la aplicación de vinazas de la industria del tequila en el cultivo del maíz y en la asociación planta-hongos micorrízicos arbusculares (hma). Centro de Investigación y Asistencia en Tecnología y Diseño del Estado de Jalisco, Mexico

Porras MA (2012) Producción de poli(hidroxialcanoato)s (PHA)s a partir de fuentes renovables de bajo costo. Dissertation. Universidad Nacional del Sur, Bahía Blanca

Porras MA, Villar MA, Cubitto MA (2017) Novel spectrophotometric technique for rapid determination of extractable PHA using Sudan black dye. J Biotechnol 255:28-32. https://doi.org/10.1016/j.jbiotec.2017.06.012

Pradhan S, Dikshit PK, Moholkar VS (2018) Production, ultrasonic extraction, and characterization of poly (3-hydroxybutyrate) (PHB) using Bacillus megaterium and Cupriavidus necator. Polym Adv Technol 29:2392-2400. https://doi.org/10.1002/pat.4351

Pramanik A, Mitra A, Arumugam M et al (2012) Utilization of vinasse for the production of polyhydroxybutyrate by Haloarcula marismortui. Folia Microbiol 57:71-79. https://doi.org/10.1007/s12223-011-0092-3

Prambudy H, Supriyatin T, Setiawan F (2019) The testing of chemical oxygen demand (COD) and biological oxygen demand (BOD) of river water in Cipager Cirebon. International Symposium on Sciences, Engineering, and Technology, Singapore, pp 0-6

Riis V, Mai W (1988) Gas chromatographic determination of poly-hydroxybutyric acid in microbial biomass after hydrochloric acid propanolysis. J Chromatogr 445:285-289

Syaichurrozi I (2016) Biogas technology to treat bioethanol vinasse. Waste Technol 4:16-23

Valappil SP, Misra SK, Boccaccini AR et al (2007) Large-scale production and efficient recovery of PHB with desirable material properties, from the newly characterised Bacillus cereus SPV. J Biotechnol 132:251-258. https:// doi.org/10.1016/j.jbiotec.2007.03.013

Vandi L, Chan CM, Werker A et al (2018) Wood-PHA composites: mapping opportunities. Polymers 2018(10):1-15. https://doi.org/10.3390/polym 10070751

Wang B, Sharma-Shivappa R, Olson J et al (2013) Production of polyhydroxybutyrate (PHB) by Alcaligenes latus using sugar beet juice. Ind Crops Prod 43:802-811. https://doi.org/10.1016/j.indcrop.2012.08.011

Yolmeh M, Jafari S (2017) Applications of response surface methodology in the food industry processes. Food Bioprocess Technol 10:413-433. https:// doi.org/10.1007/s1 1947-016-1855-2

Zanfonato K, Schmidt M, Quines LK et al (2018) Can vinasse be used as carbon source for Poly(3-hidroxybutyrate). Production by Cupriavidus necator DSM 545. Braz J Chem Eng 35:901-908

\section{Publisher's Note}

Springer Nature remains neutral with regard to jurisdictional claims in published maps and institutional affiliations. 